\title{
Prevalence of Tissue BRCA Gene Mutation in Ovarian, Fallopian Tube and Primary Peritoneal Cancer: Thai Multi-institutional Study
}

Arb-aroon Lertkhachonsuk

Mahidol University Faculty of Medicine Ramathibodi Hospital

Prapaporn Suprasert ( $\sim$ psuprase@gmail.com )

Chaing Mai University https://orcid.org/0000-0002-0205-2280

Tarinee Manchana

Chulalongkorn University

Thannaporn Kittisiam

Navamindradhiraj University

Nuttavut Kantathavorn

Chulabhorn Hospital

Tharintorn Chansoon

Ramathibodi Hospital

Surapan Khunamornpong

Chiang Mai University

Natkrita Pohthipornthawat

Chulalongkorn University

Siriwan Tangjitgamol

Navamindradhiraj University

Taksa Luasiripanthu

Chulabhorn Hospital

Chinachote Teerapakpinyo

Chulalongkorn University

Shanop Shuangshoti

Chulalongkorn University

Nareenart lemwimangsa

Ramathibodi Hospital

Wasun Chantratita

Ramathibodi Hospital

Research 
Keywords: BRCA mutation, ovarian cancer, fallopian tube cancer, peritoneal cancer

Posted Date: May 22nd, 2020

DOI: https://doi.org/10.21203/rs.3.rs-30102/v1

License: (c) (1) This work is licensed under a Creative Commons Attribution 4.0 International License. Read Full License

Version of Record: A version of this preprint was published at Asian Pacific Journal of Cancer Prevention on August 1st, 2020. See the published version at https://doi.org/10.31557/APJCP.2020.21.8.2381. 


\section{Abstract}

Background:Ovarian, fallopian tube or primary peritoneal cancer patientswith $B R C A$ gene mutation have enhanced sensitivity to platinum-based regimens and PARP inhibitors. However, the knowledgeregarding $B R C A$ mutation in Thai patients are limited. This study is to identify the prevalence and characteristics of somatic and germline BRCA1\&2mutations in Thai patients with these cancers.

Methods::The paraffin blocks of tumorsthat had histology of high grade serous or high grade endometrioid, or clear cell carcinomawhich obtained between June 2016 and December 2017 were processed to evaluate $B R C A$ mutation using next-generation sequencingsystem. Blood or normal tissue paraffin blocks of positive patients were further tested for germline $B R C A$ mutation.

Results:Tissue paraffin blocks of 178 patients were collected. Only 139 patients whose paraffin-blocks could be processed. PositiveBRCAmutation was identified in 24 cases (17.3\%): BRCA7in 13 cases, BRCA2 in 10 cases, and BRCA1\&2in another. Germline mutation study in blood or normal tissue in 23positive patients revealed $B R C A$ mutation in 14 cases: $B R C A 1$ (8 cases)and BRCA2 (6 cases). Overall, the prevalence of somatic and germline mutation were 6.5\% (9 in 138 patients) and 8.7\% (14 in 138 patients) respectively. The most common histology associated with $B R C A$ mutation was high grade serous cancer (27.3\%). No significant differencebetween,stage, outcome, platinum status and survival outcome in patients with or without $B R C A$ mutation.

Conclusion: BRCA mutation in Thai ovarian cancer patients was demonstrated in less than $10 \%$. Higher rate of mutation was found in high grade serous cancer.

\section{Background}

Epithelial ovarian cancer (EOC) is the 6th most common cancer among Thai females with the age standardized rate of 6.0 per 100,000 females [1,2]. The principal treatment for epithelial ovarian cancer (EOC), fallopian tube and peritoneal carcinoma is surgical resection of tumors along with uterus and retroperitoneal lymph node. The aim is to remove tumors as much as possible. Chemotherapy of paclitaxel and carboplatin which is the current standard regimen is given if indicated. With satisfactory surgical outcome or so called 'optimal debulking surgery' followed by this adjuvant chemotherapy regimen, response rate up to $70 \%$ can be achieved. However, the recurrence rate could be as high as $80 \%$ within 2 years especially in advanced stage [3].

Of all several prognostic factors for survival, stage is the most important: 2-year survival rates ranged from $90 \%$ in early and $40-50 \%$ in advanced stages [3]. Another important prognostic factor is the response to first-line chemotherapy or platinum-sensitivity status. If the recurrences occur either later than 6 months or sooner after the last therapy, the diseases are regarded as platinum-sensitive or platinumresistant respectively. Platinum-based chemotherapy is usually used for platinum-sensitive disease whereas other non-platinum chemotherapies would be the option for platinum-resistant disease $[3,4]$. 
Unfortunately, the patients with platinum-sensitive disease who have responded to platinum-based chemotherapy re-induction may have subsequent recurrences. The second-relapse generally have lower responses to treatment with platinum or other chemotherapeutic drugs [3, 4]. Hence, maintenance therapy after primary treatment has emerged in order to extend the progression-free period and survival.

Among drugs that are used as maintenance therapy, poly (adenosine diphosphate [ADP]) ribose polymerase (PARP) inhibitors (PARPi) is a recent agent with efficacy. PARP is an enzyme that repairs the single-strand break DNA in tumor cells. The mechanism of action of PARPi is the inhibition of this enzyme preventing DNA repair and leading to further damage to the other DNA strand or double-strand break DNA. The double-strand break DNA can be repaired to normal via homologous recombinant pathway by $B R C A 1 / 2$ gene. In the patients with $B R C A 1 / 2$ mutation, the repair mechanism cannot take place leading to cell death eventually [5-7]. Evidence-based data from previous studies showed that PARPi could prolong remission in patients especially those with platinum-sensitive recurrent ovarian cancer. This benefit of PARPi maintenance therapy on progression-free survival was evidenced especially in the patients with either germline or somatic BRCA1/2 mutation [5-8]. Hence, knowing the status of $B R C A 1 / 2$ mutation in ovarian cancer patients is important in order to support a decision making of a clinician to select an appropriate treatment option for the patients.

The prevalence of germline BRCA1/2 mutation from previous reports in Asia ranged from 14-29\%[9-11]. Higher percentages of mutation were found in some types of EOC, such as, high grade serous cancer which was found to have BRCA1/2 mutation as high as $28.5 \%$ [ 9].

With the possible ethnic influence, the prevalence of $B R C A 1 / 2$ mutation may differ across the countries. The genetic test including testing of $B R C A 1 / 2$ mutation in ovarian cancer patients had not been a standard practice in our country. Hence, the prevalence of this $B R C A 1 / 2$ gene mutation in our population remained unknown. The Thai Gynecologic Cancer Society is aware of the increasing role of PARPi in treatment for ovarian cancer, so this study was conducted among tertiary centers for cancer care in Thailand to determine the BRCA1/2 mutation status in Thai patients with EOC.

\section{Materials And Methods}

The study was approved by local Ethic Committees of each participating institution. Inclusion criteria were: Thai patients who had EOC, fallopian tube cancer and primary peritoneal adenocarcinoma (PPA); had operation between June 1, 2016 and December 31, 2017; had histopathology of high grade serous, high grade endometrioid or clear cell adenocarcinoma; had available paraffin blocks for tissue processing; and had available clinical data. In any cases of mixed cell types, these aforementioned histopathologic components must be at least $10 \%$ for the pathological processing and examination.

\section{Laboratory Data}

The representative slides containing tumor from each institution were submitted for central pathologic review by a gynecologic pathologist (S.K.) to confirm tumor histopathology and grade. The paraffin 
blocks of tumors were then randomly submitted to one of the two qualified genomic laboratories: 1) Center for Medical Genomics, Faculty of Medicine, Ramathibodi Hospital and 2) Chula GenePRO Center, Faculty of Medicine, King Chulalongkorn Memorial Hospital. Tumor cells percentage was reviewed by the pathologists (S.S). A cross-validation of the whole process from DNA extraction through data interpretation between both laboratories was executed in 10 samples before proceeding with the BRCA1 and $B R C A 2$ mutation testing in the remaining cases which were equally distributed to both laboratories.

DNA extraction and quality assessment were performed using QIAamp DNA FFPE Tissue kit and GeneRead DNA QuantiMIZE kits according to manufacturer's recommendation (Qiagen, Hilden, Germany). BRCA1 and BRCA2 mutation were analyzed using GeneReader next-generation sequencing (NGS) system (Qiagen, Hilden, Germany). Quality of sequencing data was examined using unique molecular index (UMI) coverage including $100 \mathrm{X}>90 \%$ and $60 \mathrm{X}>95 \%$ of $B R C A 1$ and BRCA2 coding regions. The samples that showed inadequate DNA quality or UMI coverage were discarded to avoid false positive and false negative results.

The variant classification was preliminarily evaluated by Ingenuity Variant Analysis (Qiagen) and manually reviewed according to the American College of Medical Genetics and Genomics (ACMG)/ the Association for Molecular Pathology (AMP) guidelines [12,13]. The final result was made from discussion and mutual agreement of both laboratories in all specimens. The patients who had tissue $B R C A 1 / 2$ mutation were counselled for germline testing. The patients, who had agreed and signed inform consent, had $5 \mathrm{cc}$ of blood drawn for germline testing using bidirectional direct sequencing. For those whose contact were not available or declined to have blood test, the genetic testing was performed using normal tissue taken from the paraffin blocks.

The prevalence of 'tissue BRCA mutation' was calculated from the number of patients who had $B R C A$ mutation from tumor tissue divided by the total number of patients who had tumor tissue testing. On the other hand, the prevalence of 'germline or somatic BRCA mutation' was calculated different. This number would be divided by the total number of patients who had tumor tissue testing but excluded those patients with tissue $B R C A$ mutation whose peripheral blood or the paraffin blocks with normal tissue were unavailable.

\section{Clinical Data}

Clinical data of the patients extracted from the patients' record files included age, stage of cancer according to the International Federation of Gynecology and Obstetrics (FIGO 2014), histopathology, dates of treatments, outcomes, status of disease and living status. The patients who developed progression during the course of chemotherapy or had recurrence within 6 months after the completion of chemotherapy were classified as platinum-refractory and -resistant, respectively or else were classified as platinum-sensitive. Progression-free survival (PFS) was calculated from the date of surgery or the date of start chemotherapy in patients who were administered neoadjuvant chemotherapy until the date of progression, recurrence, or last evaluation. Overall survival (OS) was obtained from the same date that 
using for calculated PFS to date of death or last follow-up in patients who were alive at the end of the study.

\section{Sample Size Calculation}

A target minimum sample size was calculated from the previous publication that reported $10 \%$ prevalence of $B R C A 1 / 2$ mutation in EOC [14]. With alpha error at $<0.05$ added with $10 \%$ loss of data, 160 patients were needed to be included in the study.

\section{Statistical Analysis}

Statistical analysis of the data was carried out using IBM SPSS statistics for Windows program (version 22; IBM Corporation, Armonk, NY, USA). Descriptive data were presented as number and percentages, mean with SD or median with range. Data between the patients with $B R A C 1 / 2$ mutation or normal were compared using Chi-square or Fisher's Exact test as appropriate. Survival data was analyzed with Kaplan Meier and compared between groups with log-rank test. A p-value of $<0.05$ was considered as statistical significance.

\section{Results}

A total of 178 cases from 5 cancer institutions were included in this study: Faculty of Medicine Ramathibodi Hospital, Mahidol University $(n=52)$, Chiang Mai University Hospital, Chiang Mai University $(n=44)$, King Chulalongkorn Memorial Hospital, Chulalongkorn University $(n=43)$, Faculty of Medicine and Vajira Hospital, Navamindradhiraj University $(n=31)$, and Chulabhorn Hospital, Chulabhorn Royal Academy $(n=8)$. All hospitals were in Bangkok, except for Chiang Mai University Hospital which is in the northern part of Thailand.

Basic features and clinical data of the patients are summarized in Table 1. The mean age of the patients was $56.9 \pm 11.4$ years. The majority diagnosis of the patients was cancer of ovary $(86.5 \%)$ and more than half $(57.3 \%)$ were in advanced stage. High grade serous cancer was the most common histopathology (56.7\%). Approximately $11.2 \%$ of patients had neoadjuvant chemotherapy prior to surgery whereas almost all (96.1\%) received adjuvant chemotherapy. The most common first-line chemotherapy was carboplatin plus paclitaxel (68.0\%). Complete response after primary treatment were achieved in 118 patients $(66.3 \%)$, and 55 patients $(30.9 \%)$ later developed recurrence. 


\begin{tabular}{|c|c|}
\hline Clinico-patholegical features & $\mathrm{N} \cdot \mathrm{w}]$ \\
\hline \multicolumn{2}{|l|}{ Diagnosis } \\
\hline CA Ovary & 154655 [ \\
\hline CA tube & 179.61 \\
\hline PPA & $7(3.9]$ \\
\hline \multicolumn{2}{|l|}{ Histology } \\
\hline Serous & 1016567 \\
\hline Clear cell & $69(38.8)$ \\
\hline Endometricid & $4(2.21$ \\
\hline Mixed & $4(2.2]$ \\
\hline \multicolumn{2}{|l|}{ Stage } \\
\hline i & 52029.2 \\
\hline$\|$ & $24(13.5]$ \\
\hline III & sopet.9] \\
\hline $\mathrm{N}$ & $22,12,4$ \\
\hline Neoadjuvant chemotherapy & $20 \times 11.2$ \\
\hline Adfuvant chematherapy & $171(96.1]$ \\
\hline \multicolumn{2}{|l|}{ Alegimen } \\
\hline Carbaplatin +paditaxel & 121,6809 \\
\hline Carboplatin & 12,67 \\
\hline Carboplatin + Pegylated Iiposemal doxerubicin & $37\left(208_{1}\right.$ \\
\hline Carboplatin - paditasel-Bevscizumab & 10.6 \\
\hline \multicolumn{2}{|l|}{ Outcome sitter primary chemotherspy treatment } \\
\hline \multicolumn{2}{|l|}{ Responses } \\
\hline Complete response & $1.18(66.3]$ \\
\hline Partial response & $20: 11.2$ \\
\hline Stable disease & $4(2.2)$ \\
\hline Pragression & $26 \times 146$ \\
\hline Mussing data & $10,5.64$ \\
\hline Recurrence & $5 S(309)$ \\
\hline Progression after response to chemotherapy & $23,12.9]$ \\
\hline \multicolumn{2}{|l|}{ Platinum status } \\
\hline Sensitive & $129 \times 2.5]$ \\
\hline Refractory & 18 (10.1] \\
\hline Resistant & $210118_{1}$ \\
\hline Data not available floss to follow-up: & \\
\hline
\end{tabular}

\begin{tabular}{|l|r|}
\hline Current status & 5503091 \\
Alive with disease & $89.49 .4]$ \\
Alive witheut disease & 27015.21 \\
Death & $8 \times 4.5]$ \\
Data not available ilass to follow.up: & \\
\hline
\end{tabular}

Regarding $B R C A$ results, there were only 139 patients whose paraffin-blocks could be further processed for the test. The others were disapproved due to suboptimal quality of DNA and sequencing data, and were excluded from the proceeding. Of 139 cases, the tissue $B R C A$ gene mutation was found in 24 cases (17.3\%): BRCA 1 mutation in 13 cases (9.5\%), BRCA 2 mutation in 10 (7.2\%), and both BRCA $1 \& 2$ mutation in 1 case $(0.7 \%)$. The remaining 11 cases $(7.9 \%)$ were reported to have variants of uncertain significance (VUS).

Table 2 shows $B R C A$ gene mutation according to the histology. Only high grade serous cancer and clear cell carcinoma showed positive $B R C A$ gene mutation: high grade serous cancer in 21 from 77 cases (27.3\%) and clear cell carcinoma in 3 from 55 cases (5.5\%). Of 24 patients with BRCA positive, all except one could be pursued to have germline $B R C A$ gene mutation testing using peripheral blood in 18 cases and normal tissue of myometrium from paraffin block in the other 5 cases. The results showed germline positive in 14 cases, $8 B R C A 1$ mutation and $6 B R C A 2$ mutation; 13 of which were high grade serous cancer and only 1 was clear cell carcinoma. Thus, among 138 cases who had the data of both germline and somatic, the percentages of germline BRCA gene mutation was $8.7 \%$ (14 in 138 cases) while the percentage of somatic $B R C A$ gene mutation was $6.5 \%$ (9 in 138 cases). The detail of somatic $B R C A$ mutation in all 9 patients were 4 BRCA 1 mutation, 4 BRCA2 mutation, and 1 BRCA1\&2 mutation. The patients who had germline mutation was significantly younger than and the patients with only somatic 
mutation ( $48.4 \pm 10.6$ versus $61.6 \pm 12.9$ years $P=0.014$ ). Thus, at least the prevalence rates of germline and somatic BRCA mutation in our study were $8.7 \%$ and $6.5 \%$, respectively.

Table 2: $B R C A$ gene mutation according to the histology ( $\mathrm{N}=139$ )

\begin{tabular}{|c|c|c|c|c|c|c|c|}
\hline \multirow[t]{3}{*}{ Histology } & \multicolumn{7}{|c|}{ BRCA result (as) } \\
\hline & \multicolumn{4}{|c|}{ Positive } & \multirow[t]{2}{*}{ Negative } & \multirow[t]{2}{*}{ VUS } & \multirow[t]{2}{*}{ Total } \\
\hline & BRCA1 & $B R C A 2$ & $B R C A 1 \& 2$ & Total & & & \\
\hline Serous & $13(16.9)$ & $7(9.1)$ & $1(1.3)$ & $21(27.3)$ & $49(63.6)$ & $7(9.1)$ & 77 \\
\hline Clear & - & $3(5.5)$ & - & $3(5.5)$ & $48(87.3)$ & $4(7.3)$ & 55 \\
\hline Endometrioid & - & $\cdot$ & - & - & $4(100)$ & - & 4 \\
\hline Mixed & - & - & - & $\cdot$ & $3(100)$ & - & 3 \\
\hline Total & $13(9.4)$ & $10(7.2)$ & $1(0.7)$ & $24(17.3)$ & $104(74.8)$ & $11(7.9)$ & 139 \\
\hline
\end{tabular}

VUS = Variant of Uncertain significance

Mixed histology included endometrioid caecinoma - clear cell carcinoma (2 cases), high

grade serous carcinoma + celar cell carcinoma (1 case)

Table 3 summarizes the detail of BRCA gene mutation identified by next generation sequencing. Three mutation patterns were identified including 11 frameshifts, 9 nonsenses, and 2 missenses. Missense mutations were observed only in BRCA2 genes while frameshift and nonsense were found in both $B R C A 1$ and $B R C A 2$. Five novel mutations in 6 patients were observed whereas the others were known mutations reported in the NCBI database of genetic variation (dbSNP) [15].

Table 3 Detail of $B R C A$ mutation in 24 patients

\begin{tabular}{|c|c|c|c|c|c|c|c|c|}
\hline \multirow[b]{2}{*}{ No. } & \multirow[b]{2}{*}{ Gene } & \multicolumn{4}{|c|}{ Mutation } & \multirow[b]{2}{*}{ Histology } & \multirow{2}{*}{$\begin{array}{c}\text { Age of } \\
\text { diagnosis } \\
\text { (years) }\end{array}$} & \multirow[b]{2}{*}{ Germline / Somatic } \\
\hline & & Nucleotide change & Amino acid change & $\begin{array}{l}\text { Type of } \\
\text { mutation }\end{array}$ & dbSNP & & & \\
\hline 1 & $B R C A I$ & c.624_625ins_AGGGATGA_AATCAGGAAACCA & p/Pro209fsX) & Frameshift & $\mathrm{r} 3397509302$ & Serous & 53 & Germline \\
\hline 2 & $B R C A I$ & c.697delG & $\mathrm{p}$ (Val233Ter) & Nonsenge & rs1555593298 & Serous & 64 & Somatic \\
\hline 3 & $B R C A I$ & c.1265_1266dupAT & p.Ser423IlefsX) & Frameghift & $\mathrm{rs} 397508850$ & Serous & 23 & Germline \\
\hline $4 * *$ & $B R C A I$ & c.1544_1550delAGGATTT & p.(Glu515fsX15) & Frameghift & - & Serous & 31,57 & Germline, Germline \\
\hline 5 & $B R C A I$ & c. $1789 \mathrm{G}>\mathrm{T}$ & p.Glu597Ter) & Nonsense & $\mathrm{r} 555650082$ & Serous & 48 & Germline \\
\hline $6 *$ & $B R C A 1$ & c.1961delA & p.Lys654SerfaX) & Frameghift & rs80357522 & Serous & 61 & Somatic \\
\hline 7 & $B R C A I$ & c.2462dupA & p.Asp821GlufaX2) & Frameghift & . & Serous & 78 & Somatic \\
\hline 8 & $B R C A I$ & $c .2719 \mathrm{G}>\mathrm{T}$ & p/Glug07Ter & Nonsense & rs8876658593 & Serous & 47 & Germline \\
\hline $9 *$ & $B R C A I$ & $c .3037 \mathrm{G}>\mathrm{T}$ & p/Glu1013Ten & Nonsenge & . & Serous & 58 & Germline \\
\hline 10 & $B R C A I$ & c.3181delA & p/1lel061Ten & Nonsense & $\mathrm{r} 380357702$ & Serous & 54,56 & NA*t, Germline \\
\hline $11 \%,+\infty$ & $B R C A I$ & $c .3769 \mathrm{G}>\mathrm{T}$ & p.(Glu1257Ter) & Nonsense & - & Serous & 58 & Somatic \\
\hline $12 *$ & $B R C A I$ & c.4905_4914delGA_AGCCAGA.A & p.(Glu1635A.spfaX) & Frameshift & $-\cdot$ & Serous & 45 & Somatic \\
\hline 13. & $B R C_{412}$ & c. $145 \mathrm{G}>\mathrm{T}$ & $\mathrm{p}$ (Glu49Ter) & Nonsense & rs 80358435 & Serous & 58 & Somatic \\
\hline 14 & $B R C A 2$ & c.755_758delACAG & p/Asp252ValfsX24) & Frameshift & rs80359659 & Serous & 51 & Germline \\
\hline 15 & $B R C A 2$ & c.1321_1324delACTT & $\mathrm{p}(\mathrm{Thr} 44 \mathrm{GGlnfaX18)}$ & Frameshift & rs1064793572 & Serous & 64 & Germline \\
\hline 16 & $B R C_{412}$ & c.1399_1402del_AAGA & p/Lys467GlufsX17) & Frameghift & $\mathrm{rs398122726}$ & Clear cell & 46 & Germline \\
\hline 17 & $B R C A 2$ & c.1813delA & p.(lle605TyrfsX9) & Frameghift & rs80359306 & Clear cell & 56 & Somatic \\
\hline 18 & $B R C A 2$ & $c 4222 \mathrm{C}>\mathrm{T}$ & $\mathrm{p} /$ Glnl408Ter & Nonsenge & rs80358663 & Serous & 69 & Somatic \\
\hline 19 & $B R C_{A 12}$ & c.4593dupA & p.(Vall532SerfsX2) & Frameshift & r3397507731 & Clear cell & 43 & Somatic \\
\hline 20 & $B R C_{42}$ & c. $7090 \mathrm{G}>\mathrm{T}$ & p.Glu22364Ter) & Nonsense & rs80358940 & Serous & 80 & Somatic \\
\hline 21 & $B R C_{42}$ & $\mathrm{c} .8009 \mathrm{C}>\mathrm{T}$ & $\mathrm{p}$ (Ser2670Leu) & Misgense & rs80359035 & Serous & 50 & Germline \\
\hline 22 & $B R C_{A 2}$ & $c .9154 \mathrm{C}>\mathrm{T}$ & p.Arg3052Trp) & Misgense & $\mathrm{rs} 45580035$ & Serous & 45,48 & Germline, Germline \\
\hline
\end{tabular}

This study could not demonstrate any differences of age, type of cancer, stage, outcome after primary treatment, and platinum-sensitivity status of the patients with and without tissue $B R C A$ gene mutation (Table 4). Figure 1\& Fig. 2 also revealed no differences of 2-year PFS and 2-year OS between the two groups of patients. However, the OS in patients with pathogenic BRCA gene tended to be better with 2- 
year OS of $95.0 \%$ (95\% confidence interval $77.6-96.8 \%$ ) compared to $87.2 \%$ (95\% confidence interval $88.8-100 \%)$ in patients without pathogenic $B R C A$ gene $(P=0.077)$.

Table 4: Clinical data of the patients according to $B R C A$ results $(N=139)$

\begin{tabular}{|c|c|c|c|}
\hline & \multicolumn{2}{|c|}{$\mathrm{BRCA}$} & \multirow[t]{2}{*}{ P value } \\
\hline & $\begin{array}{c}\text { Pathogenic } \\
(\mathrm{N}=24)\end{array}$ & $\begin{array}{c}\text { Non-pathogenic } \\
\qquad(\mathrm{N}=115)\end{array}$ & \\
\hline Mean age & 54.0 & 56.9 & $0.27 *$ \\
\hline $\begin{array}{l}\text { Diagnosis } \\
\text { Ovary } \\
\text { Fallopian tube } \\
\text { PPA }\end{array}$ & $\begin{array}{c}21(87.5) \\
3(12.5) \\
-\end{array}$ & $\begin{array}{c}103(89.6) \\
9(7.8) \\
3(2.6)\end{array}$ & $0.69 \#$ \\
\hline $\begin{array}{c}\text { Stage } \\
\text { I } \\
\text { II } \\
\text { III } \\
\text { IV }\end{array}$ & $\begin{array}{c}2(8.3) \\
5(20.8) \\
12(50.0) \\
5(20.8)\end{array}$ & $\begin{array}{l}37(32.2) \\
15(13.0) \\
48(41.7) \\
15(13.0)\end{array}$ & $0.07 \#$ \\
\hline $\begin{array}{l}\text { Outcome after primary treeatment } \\
\text { Complete response } \\
\text { Partial response } \\
\text { Stable disease } \\
\text { Progression } \\
\text { Data not available }\end{array}$ & $\begin{array}{c}18(75.0) \\
2(8.3) \\
0 \\
2(8.3) \\
2(8.3) \\
\end{array}$ & $\begin{array}{c}77(67.0) \\
14(12.2) \\
3(2.6) \\
15(13.0) \\
6(5.2) \\
\end{array}$ & $0.88 \#$ \\
\hline $\begin{array}{l}\text { Platinum-sensitivity status } \\
\text { Sensitive } \\
\text { Refractory } \\
\text { Resistant } \\
\text { Data not available }\end{array}$ & $\begin{array}{c}21(87.5) \\
0 \\
1(3.3) \\
2(8.3)\end{array}$ & $\begin{array}{c}85(73.9) \\
8(7.0) \\
16(13.9) \\
6(5.2)\end{array}$ & $0.28 \#$ \\
\hline
\end{tabular}

Non-pathogenic = BRCA negative - VUS (VUS = Variant of Uncertain significance)

\#Fisher Exact test

-Chi-square test

\section{Discussion}

The present study found tissue BRCA mutation in high grade EOC, fallopian tube cancer and primary peritoneal adenocarcinoma in 24 from 139 patients (17.3\%). Of 23 from 24 patients, 14 patients revealed germline BRCA 1/2 mutations. Thus, the prevalence of germline and somatic BRCA mutation in our study were at least $10.1 \%$ (14 in 138 cases) and 6.5\% (9 in 138 cases), respectively. These rates corresponded to the Taiwanese's study. Chao et al. [16] investigated the occurrence of BRCA 1/2 mutation in 99 Taiwanese ovarian cancer patients from formalin-fixed paraffin-embedded tumor samples of tumor and normal tissue by using next-generation sequencing, and found BRCA 1 in 7 cases and BRCA 2 in 6 cases. Therefore, the prevalence rate of their study was $12.1 \%$, and 4 cases (4\%) were proved somatic mutation. Another study from Thailand by Manchana et al. [17] identified the frequency of BRCA mutation in 87 Thai high grade serous cancer and high grade endometrioid ovarian cancer, including the fallopian and peritoneal cancer. The authors used peripheral blood DNA samplers or DNA extracted from formalin-fixed paraffin embedded blocks (FFPE) or a fresh tumor specimen to analyze BRCA mutation via the next generation sequencing system. The results showed germline BRCA mutation detection in 19 patients 
(21.8\%), 14 of them (16.1\%) with BRCA1 mutation, and 5 of them (5.7\%) with BRCA2 mutation. All positive patients revealed histology as high grade serous cancer. The different detection rates of BRCA mutation between our study and Manchana's study were probably from the differed specimens. Our study used only FFPE that might decrease the detection rate due to the variability of tumor samples and intratumoral heterogeneity which probably compromised the representativeness of the sample [18] whereas Manchana et al. used fresh tumor specimen or blood samples aside from FFPE to analyze BRCA[17].

The most frequent histology in patients with germline $B R C A$ mutation was high grade serous carcinoma in a range of $5.5-16.7 \%$, followed by endometrioid carcinoma (4.3-13\%) and clear cell carcinoma (6.3$9.1 \%)[18,19]$. However, in the present study, tissue BRCA mutation was found in $27.3 \%$ of high grade serous carcinoma and $5.5 \%$ of clear cell carcinoma, while none in endometrioid carcinoma. This nonsimilar outcome might be from very small number of patients with high grade endometrioid carcinoma in our study. However, BRCA2 mutation was found only in clear cell carcinoma. This finding corresponded to the previous reports that suggested that $B R C A 2$ mutation are common in this cell type [20,21]. However, 2 from 3 patients with clear cell carcinoma had somatic BRCA2 mutation $(87.7 \%)$ and only 1 patient (33.3\%) had germline BRCA2 mutation.

Due to variable from prevalence of $B R C A$ mutation among various histology, the current recommendation of the American Society of Clinical Oncology (ASCO) guideline is to assess either germline or somatic BRCA gene mutation in all non-mucinous ovarian, fallopian tube and peritoneal cancer of high grade [22]. Improvement of treatment outcome is possible with PARPi [5-7, 18, 23]. Gori et al. [24] summarized an initial step of $B R C A$ mutation gene investigation by studying $B R C A 1 / 2$ mutation on tumor tissue. The test which could identify spectrum of genomic rearrangements (i.e., deletions or duplications of one or more exons, or of the whole gene) yielded high sensitivity. In the patients whose tissues were positive for $B R C A 1 / 2$ mutation, genetic counseling and further investigation for germline mutation from their peripheral blood should be deferred as the next step of investigation. If the blood test was positive, these patients would benefit from PARPi therapy and should be under close surveillance for a possible development of second malignancy.

The major problem of tissue sample for testing pathogenic gene was the quality of FFPE clinical specimens. Although next generation sequencing that we used can sequence entire BRCA $1 / 2$ coding regions, epigenetic and structural change were limited to detect in this study. Thirty nine DNA samples (21.9\%) were unable to obtain BRCA mutation status due to insufficient DNA quality. Various factors affected FFPE DNA quality in molecular genomics test such as tissue fixation time, storage time and archive temperature [25]. In this study, we selected FFPE tissues blocks during June 2016 to December 2017 and finished the DNA extraction within 2018 (< 3 years) to avoid long-term storage effect. Therefore, fixation time and archive temperature would be causes of low DNA quality since the samples were collected from 5 institutions and there might be deviation of FFPE tissue handling and collection.

Regarding clinical characteristics between the patients with and without $B R C A$ gene mutation, the present study did not find any significant differences of age, disease, stage, primary outcome, and platinum- 
sensitivity status, and survivals after treatment. Previous study by Kuberlac et al. [26] reported that their patients with both germline and somatic BRCA mutation had younger age and had significantly higher rate of complete pathologic response during the first and second platinum-sensitive relapse, and longer overall survival for advanced stage treated with neo-adjuvant chemotherapy when compared to 52 patients without $B R C A$ mutation. Although this study also found younger age among $B R C A$ mutation, the positive $B R C A$ gene did not serve as a favorable prognostic factor. The small number of patients in this study may limit any meaningful clinical summary regarding the prognostic role of $B R C A$ mutation.

In conclusion, tissue BRCA $1 / 2$ mutation positive was presented in about $17 \%$ of high grade epithelial ovarian, fallopian and peritoneal cancer. The most frequent histology was the serous cancer. The quality of paraffin block preservation should be concerned in order to improve the detection rate of this $B R C A$ mutation.

\section{Conclusion}

BRCA mutation in Thai ovarian cancer patients was demonstrated in less than $10 \%$. Higher rate of mutation was found in high grade serous cancer

\section{Declarations}

\section{Ethics approval}

The study was approved by local Ethic Committees of each participating institution and had consent to participate.

Mahidol University: MURA2018/487

Chiang Mai University: OBG-12561-05448/ 200/2561

Chulalongkorn University: 959-2508

Navamindradhiraj University: COA 142/2561

Chulabhorn Hospital: 031-2561

\section{Consent for publication:}

Not applicable

\section{Availability of data and materials}


The datasets used and/or analyzed during the current study are available from the corresponding author on reasonable request

\section{Competing interests}

All authors declare that they have no conflicts of interest to disclose

\section{Funding:}

This study was supported by Astra ZenecaThailand which mostly provided the cost of genetic sequencing.Howecer, the funders had no role instudy design, data collection and analysis, decision to publish, or preparation of the manuscript.

\section{Authors' contributions}

P.S and A.Lconceived of the presented idea. PS,AL,TM,TK,NKdeveloped the theory and performed the computations. TC,SK,NP,ST and TL verified the analytical methods (Patho.) PS, CT,SS,NI,WC verified the analytical methods (LAB). ST,TM,AL, supervised the findings of this workfor PS. All authors discussed the results and contributed to the final manuscript.

\section{Acknowledgement:}

Thai Gynecologic Cancer Institute (TGCS) : for support this project

\section{References}

1. Wilailak S, Lertchaipattanakul N. The epidemiologic status of gynecologic cancer in Thailand.J Gynecol Oncol. 2016;27. https://doi.org/10.3802/jgo.2016.27.e65.

2. Torre LA, Trabert B, DeSantis CE, Miller KD, Samimi G, Runowicz CD, et al. Ovarian cancer statistics, 2018. CA Cancer J Clin. 2018;68:284-96. https://doi.org/10.3322/caac.21456.

3. Webber K, Friedlander M.Chemotherapy for epithelial ovarian, fallopian tube and primary peritoneal cancer.Best Pract Res Clin Obstet Gynaecol 2017;41:126-38. https://doi:10.1016/j.bpobgyn.2016.11.004.

4. Jansaka N, Suprasert P. Survival outcomes of recurrent epithelial ovarian cancer: experience from a Thailand northern tertiary care center. Asian Pac J Cancer Prev. 2014;15:10837-40. https://doi.org/10.7314/APJCP.2014.15.24.10837.

5. Pujade-Lauraine E, Ledermann JA, Selle F, Gebski V, Penson RT, Oza AM,et al. Olaparib tablets as maintenance therapy in patients with platinum-sensitive, relapsed ovarian cancer and a BRCA1/2 
mutation (SOLO2/ENGOT-OV21): a double-blind, randomised, placebo-controlled, phase 3 trial.Lancet Oncol 2017;18:1274-84.https://doi.org/10.1016/S1470-2045(17)30469-2

6. Ledermann J, Harter P, Gourley C, Friedlander M, Vergote I, Rustin G, et al. Olaparib maintenance therapy in patients with platinum-sensitive relapsed serous ovarian cancer: a preplanned retrospective analysis of outcomes by BRCA status in a randomised phase 2 trial.Lancet Oncol 2014;15:852-61.https://doi.org/10.1016/S1470-2045(14)70228-1

7. Hennessy BT, Timms KM, Carey MS, Gutin A, Meyer LA, Flake DD 2. Somatic mutations in BRCA1 and BRCA2 could expand the number of patients that benefit from poly (ADP ribose) polymerase inhibitors in ovarian cancer. J Clin Oncol. 2010;28:3570-6. https://doi. nd, et al. ;. : 10.1200/JCO.2009.27.2997.

8. Cancer Genome Atlas Research Network. Integrated genomic analyses of ovarian carcinoma. Nature. 2011;474(7353):609-15. https://doi.org/10.1038/nature10166.

9. Enomoto T, Aoki D, Hattori K, Jinushi M, Kigawa J, Takeshima N,et al. The first Japanese nationwide multicenter study of $B R C A$ mutation testing in ovarian cancer: CHARacterizing the cross-sectionaL approach to Ovarian cancer geneTic TEsting of BRCA (CHARLOTTE).Int J Gynecol Cancer2019;29:1043-9.http://dx.doi.org/10.1136/ijgc-2019-000384

10. Kwon BS, Byun JM, Lee HJ, Jeong DH, Lee TH, Shin KH, et al.Clinical and Genetic Characteristics of BRCA1/2 Mutation in Korean Ovarian Cancer Patients: A Multicenter Study and Literature Review.Cancer Res Treat2019;51:941-50.https://doi.org/10.4143/crt.2018.312

11. Wu X, Wu L, Kong B, Liu J, Yin R, Wen H, et al.The First Nationwide Multicenter Prevalence Study of Germline BRCA1 and BRCA2 Mutations in Chinese Ovarian Cancer Patients.Int J Gynecol Cancer2017;27:1650-7.http://dx.doi.org/10.1097/IGC.0000000000001065.

12. Richards S, Aziz N, Bale S, Bick D, Das S, Gastier-Foster J,et al. Standards and guidelines for the interpretation of sequence variants: a joint consensus recommendation of the American College of Medical Genetics and Genomics and the Association for Molecular Pathology.Genet Med 2015;17:405-24.https://doi.org/10.1038/gim.2015.30

13. Li MM, Datto M, Duncavage EJ, Kulkarni S, Lindeman NI, Roy S,et al.Standards and Guidelines for the Interpretation and Reporting of Sequence Variants in Cancer: A Joint Consensus Recommendation of the Association for Molecular Pathology, American Society of Clinical Oncology, and College of American Pathologists.J Mol Diagn 2017;19:423.https://www.ncbi.nIm.nih.gov/pmc/articles/PMC5707196/

14. Zhao Q, Yang J, Li L, Cao D, Yu M, Shen K,et al. Germline and somatic mutations in homologous recombination genes among Chinese ovarian cancer patients detected using next-generation sequencing.J Gynecol Oncol 2017;28:e39.https://doi.org/10.3802/jgo.2017.28.e39

15. https://. Internet Accessed 15/4/20.

16. Chao A, Chang TC, Lapke N, Jung SM, Chi P, Chen $\mathrm{CH}$,et al.Prevalence and clinical significance of BRCA1/2 germline and somatic mutations in Taiwanese patients with ovarian cancer.Oncotarget 2016;7:85529-41.https://doi.org/10.18632/oncotarget.13456

Page $13 / 16$ 
17. Manchana T, Phoolcharoen $\mathrm{N}$, Tantbirojn $\mathrm{P}$. BRCA mutation in high grade epithelial ovarian cancers.Gynecol Oncol Rep 2019;29:102-5. https://doi. 10.1016/j.gore.2019.07.007

18. 10.6061/clinics/2018/e450s da Cunha Colombo Bonadio RR, Fogace RN, Miranda VC, Diz MDPE. Homologous recombination deficiency in ovarian cancer:a review of its epidemiology and management.Clinics (Sao Paulo) 2018;73:e450s. http://dx.doi.org/10.6061/clinics/2018/e450s

19. Vergote I, Banerjee SGerdes AM, van Asperen C, Marth C,Vaz F,et al. Current perspectives on recommendations for BRCA genetic testing in ovarian cancer patients.Eur J Cancer 2016;69:12734.https://doi.org/10.1016/j.ejca.2016.10.006

20. Goodheart MJ, Rose SL, Hattermann-Zogg M, Smith BJ, De Young BR, Buller RE. BRCA2 alteration is important in clear cell carcinoma of the ovary.Clin Genet2009;76:1617.https://doi.org/10.1111/j.1399-0004.2009.01207.x

21. Manchana T, Phowthongkum P, Teerapakpinyo C.Germline mutations in Thai patients with nonmucinous epithelial ovarian cancer.World J Clin Oncol2019;10:35868.https://www.wjgnet.com/2218-4333/full/v10/i11/358.htm

22. Konstantinopoulos PA, Norquist B, Lacchetti C, Armstrong D, Grisham RN, Goodfellow PJ,et al.Germline and Somatic Tumor Testing in Epithelial Ovarian Cancer: ASCO Guideline.J Clin Oncol 2020;38:1222-45.https://ascopubs.org/doi/abs/10.1200/JC0.19.02960

23. Dougherty BA, Lai Z, Hodgson DR, Orr MCM, Hawryluk M, Sun J,et al. Biological and clinical evidence for somatic mutations in BRCA1 and BRCA2 as predictive markers for olaparib response in highgrade serous ovarian cancers in the maintenance setting.Oncotarget 2017;8:4365361.https://doi.org/10.18632/oncotarget.17613

24. Gori S, Barberis M, Bella MA, Buttitta F, Capoluongo E, Carrera P,et al. Recommendations for the implementation of BRCA testing in ovarian cancer patients and their relatives.Crit Rev Oncol Hematol 2019;140:67-72.https://doi.org/10.1016/j.critrevonc.2019.05.012

25. Einaga N, Yoshida A, Noda H, Suemitsu M, Nakayama Y, Sakurada A,et al. Assessment of the quality of DNA from various formalin-fixed paraffin-embedded (FFPE) tissues and the use of this DNA for next-generation sequencing (NGS) with no artifactual mutation.PLoS One2017;12:e0176280.https://doi.org/10.1371/journal.pone.0176280

26. Kubelac P, Vlad C, Berindan Neagoe I, Irimie A, Achimas Cadariu P. The clinical features associated with mutated BRCA1 and 2 genes in ovarian cancer patients.J BUON 2019;24:153843.https://www.jbuon.com/archive/24-4-1538.pdf

\section{Figures}




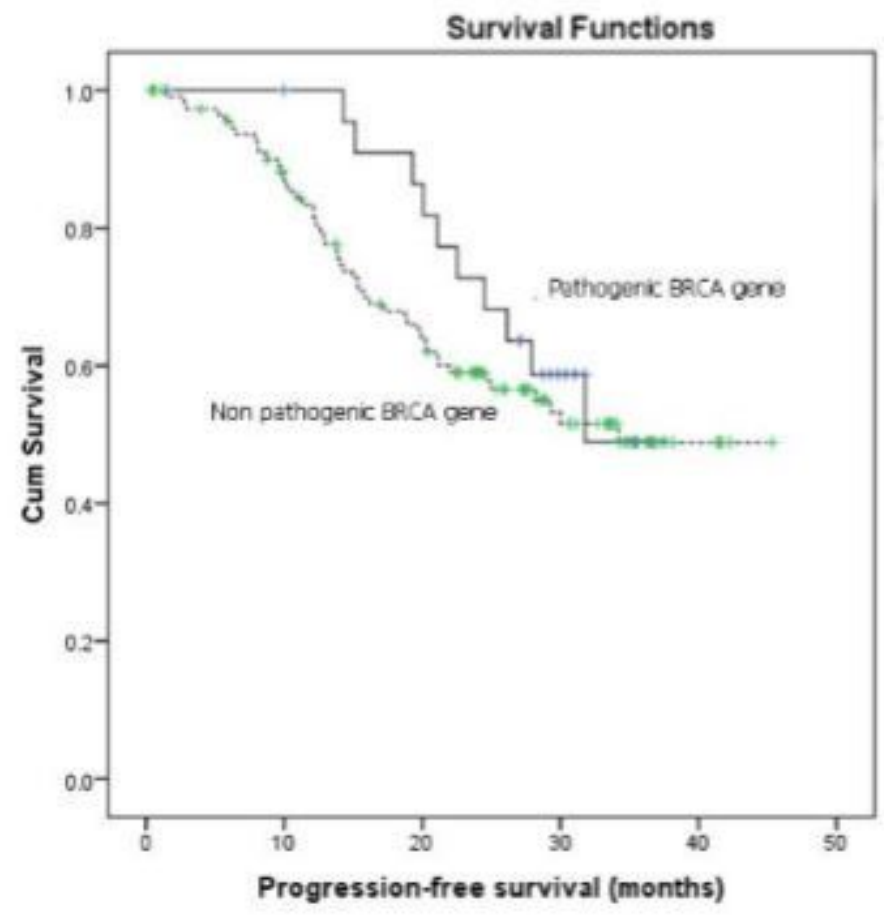

Median progression free survival:

Pathogenic $B R C A$ gene $=31.8$ months vs. non-pathogenic $B R C A$ gene $=30$ months

2 year progression free survival:

Pathogenic $\mathrm{BRCA}$ gene $=68.2 \%(95 \% \mathrm{Cl} 48.8-87.6 \%)$ vs. non- Pathogenic $\mathrm{BRCA}$ gene $=59 \%(95 \% \mathrm{Cl}$

49.6-68.4)

Log rank test $P=0.43$

$\mathrm{Cl}=$ confidence interval

\section{Figure 1}

Progression - free survival in patients with and without pathogenic BRCA gene 


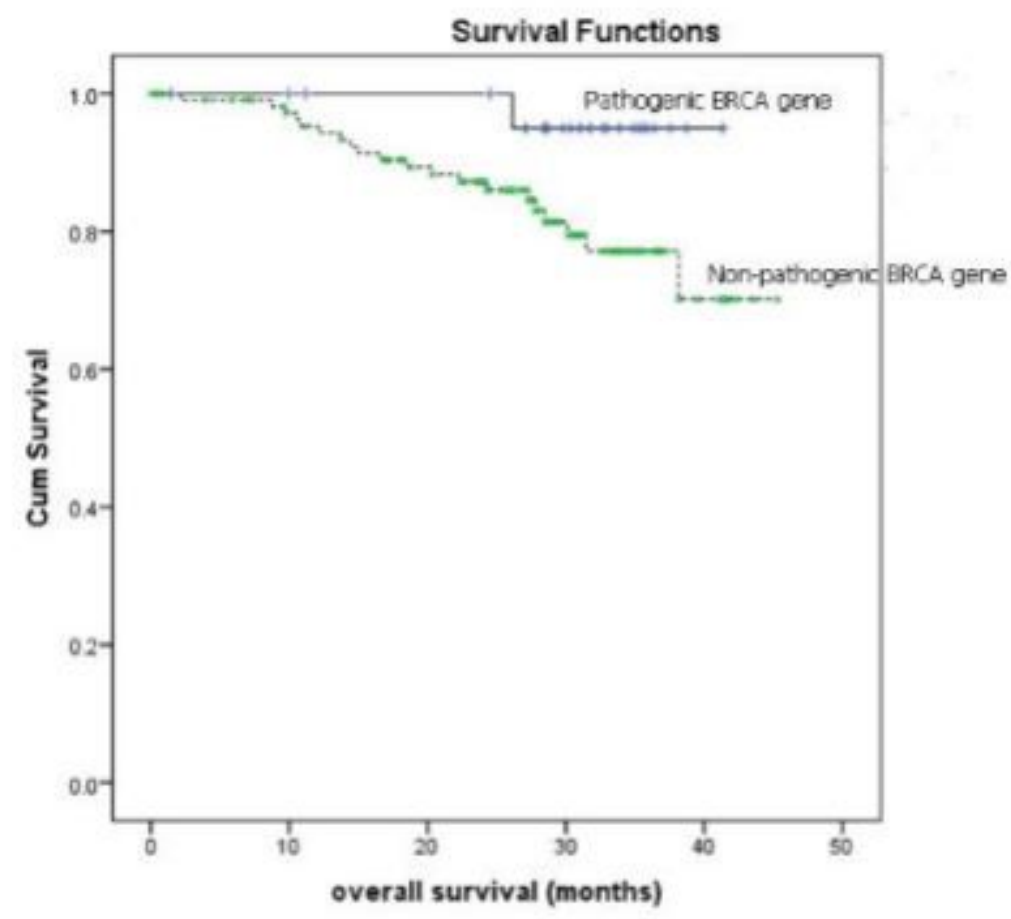

Log rank test $P=0.077$

2-yrs overall survival : non-pathogenic BRCA gene $=87.2 \%, 95 \% \mathrm{Cl} 88.8-100 \%$, pathogenic $\mathrm{BRCA}$ gene $=95 \%(95 \% \mathrm{Cl} 77.6-96.8 \%$

$\mathrm{Cl}=$ confidence interval

Figure 2

Overall survival (OS) in patients with and without pathogenic BRCA gene

\section{Supplementary Files}

This is a list of supplementary files associated with this preprint. Click to download.

- supplement.docx 